\title{
Policy evaluation of vehicle exhaust standards in Japan from 1995 to 2005 based on two human health risk indices for air pollution and global warming
}

\author{
Naoya Kojima $^{1} \cdot$ Akihiro Tokai $^{1} \cdot$ Toyohiko Nakakubo $^{2} \cdot$ Yusuke Nagata $^{3}$
}

Published online: 3 February 2016

(c) The Author(s) 2016. This article is published with open access at Springerlink.com

\begin{abstract}
Measures for vehicle exhaust emissions aimed at reducing either air pollution or global warming could have counterproductive effects on one another. Increasing diesel passenger vehicles, which generally have lower $\mathrm{CO}_{2}$ emissions than gasoline counterparts, leads to increasing particulate matter (PM) emissions, while gasoline has lower PM emissions than diesel. It is said that stringent limits on PM emission factors discourages improved $\mathrm{CO}_{2}$ emission factors. Without including both effects in a risk evaluation, one cannot evaluate whether the total risk is reduced or not. Hence, we evaluated representative exhaust emission measures based on risk evaluation for both air pollution and global warming. Considering consumer choice between diesel and gasoline passenger vehicles and emissions standards adopted in Japan from 1995 to 2005, we built five cases for vehicle policy evaluation. For each case, we estimated disability-adjusted life years (DALY) as an index of human health risk caused by lung cancer linked to inhalation exposure of elemental carbon in PM as well as due to global warming linked to $\mathrm{CO}_{2}$. The results of our
\end{abstract}

Electronic supplementary material The online version of this article (doi:10.1007/s10669-015-9582-1) contains supplementary material, which is available to authorized users.

Naoya Kojima

kojima@em.see.eng.osaka-u.ac.jp

1 Division of Sustainable Energy and Environmental Engineering, Graduate School of Engineering, Osaka University, 2-1 Yamadaoka, Suita-shi, Osaka 565-0871, Japan

2 Natural Science Division, Faculty of Core Research, Ochanomizu University, 2-1-1, Otsuka, Bunkyo-ku, Tokyo 112-8610, Japan

3 Mazda Motor Corporation, 3-1 Shinchi, Fuchu-cho, Aki-gun, Hiroshima 730-8670, Japan risk evaluation reveal that the case adopting the 2005 new long-term Japanese emission standard reduces the human health risk caused by lung cancer due to air pollution by $0.6 \times 10^{3}$ DALY, but would increase the risk due to global warming by $31.9 \times 10^{3}$ DALY compared with the case of adopting EURO 4, for the same conditions of passenger vehicle choice from 1995. These results suggest that the characteristics of Japanese emissions standards are mainly designed to reduce air pollution.

Keywords Risk evaluation - Policy evaluation - DALY . Vehicle exhaust emissions $\cdot \mathrm{PM} \cdot \mathrm{CO}_{2}$

\section{Introduction}

The importance of decision-making based on quantitative risk evaluation has been extensively reviewed (Linkov et al. 2014), with many discussions arguing for institutionalization of this process. Although vehicle exhaust emissions have been considered to be a significant risk source due to air pollution and global warming, risk-based decision-making has not yet been used for management of risks associated with vehicle exhaust emissions. We believe that the trade-off between reducing air pollution and greenhouse-gas (GHG) emissions becomes difficult in quantitative risk evaluation. In fact, the Central Environment Council (CEC) of Japan (1997) reported qualitatively that exhaust emissions and fuel economy (closely related to $\mathrm{CO}_{2}$ emissions), in particular, exhibited a marked trade-off relationship, making it extremely difficult to significantly reduce exhaust emissions while improving fuel efficiency at the same time.

In Japan, air pollution from vehicle exhaust has been improved by introducing command and control strategies 
such as specification of vehicle emissions standards and environmental standards. In particular, the Japanese government has discussed this since 1997 (CEC 1997), and by 2002 introduced the 2005 new long-term standards (CEC 2002). In contrast to Japan, the EU introduced the EURO 4 standard in 1998 (EU 1998). The Japanese standard required lower $\mathrm{NO}_{x}$ and particulate matter (PM) emissions from passenger vehicles compared with the EU standard. Considering the trade-off mentioned above, these countermeasures could have counterproductive effects on one another in terms of environmental risk.

In a risk analysis considering such trade-offs, Tengs et al. (1995) evaluated and compared 500 interventions based on quantitative results for cost-effectiveness in terms of life-years saved as estimated by two trained reviewers who reviewed documents for each intervention based on three criteria. This study indicated that use of a common analytical framework and evaluation index for reevaluating risks enables incorporation of various quantitative measures. As vehicles emit not only air pollutants but also greenhouse gases, the impact of countermeasures on emissions needs to be evaluated using a common index for these different kinds of emissions. To address this issue, disability-adjusted life years (DALY) (Murray and Lopez 1996) have been employed to evaluate the comparative risk context. DALY consists of years of life lost (YLL) as well as years lost due to disability (YLD).

To predict future strategy directions toward implementing risk-based decision-making for exhaust emissions management, we focused on determining characteristics of past decisions based on risk evaluations, but considering risks as trade-offs. Therefore, our research objectives are: (1) to evaluate past measures for vehicle exhaust emissions in terms of major human health risks caused by air pollution and global warming, and (2) to evaluate the characteristics of past Japanese measures based on a human health risk evaluation, comparing both actual and virtual measures. In our study, we used two main variables: the choice of passenger vehicle between diesel passenger vehicle (D-PV) and gasoline passenger vehicle (G-PV), and the vehicle exhaust emissions standards in Japan from 1995 to 2005. To assess human health risk, we built cases for risk comparison using a combination of these two variables.

\section{Framework}

To evaluate past measures, we built cases that reflect actual past measures as well as hypothetical ones for comparison. To evaluate human health risks, we employed a unified index and compared risks at different time points. Our main analytical boundary conditions are described below.

\subsection{Target area}

To evaluate the effectiveness of Japanese regulatory decisions, the target area was Japan.

\subsection{Time period}

The chosen time period was 2005 .

\subsection{Target risk}

We focused on PM, as one of the most concerning air pollution indicators, and $\mathrm{CO}_{2}$, as a representative $\mathrm{GHG}$ causing global warming. In our risk evaluation for PM, we focused on lung cancer caused by inhalation exposure to elemental carbon (EC) in diesel exhaust particles (DEP) based on data from the California Environmental Protection Agency, USA (California EPA 1998). We regarded DEP as PM from D-PV, but not from G-PV. In our risk evaluation for $\mathrm{CO}_{2}$, we focused on five human disease indicators (malaria, diarrhea, malnutrition, drowning, and cardiovascular disease) reflecting global warming related to $\mathrm{CO}_{2}$, after Schryver et al. (2009).

\subsection{Risk evaluation}

We employed a typical procedure for evaluating human health risk caused by lung cancer linked to EC or caused by global warming linked to $\mathrm{CO}_{2}$. For EC-related risks, we estimated the DALY and the excess lifetime lung cancer risk at the 95th percentile for the Japanese population. For $\mathrm{CO}_{2}$-related risks, we estimated the DALY impact caused by global warming. The DALY index was employed for comparison of human health risks at different endpoints, or for determination of the total human health risk for all cases. The other index used for comparison was an estimated lifetime risk of less than $10^{-5}$, corresponding to what is known as the virtually safe dose (Gaylor 1989). These two indices were used to compare risks in the tradeoff and to determine the characteristics of measures in each case.

\subsection{Case settings}

We focused on actual measures used from 1995 to 2005 in Japan. We selected this period because 1995 was the year when the holding D-PV composition ratio began to decrease in Japan, whereas in Europe, increasing D-PV ratios occurred from the 1990s (Cames and Helmers 2013). This change from D-PV to G-PV was a specific one, and we expected this change to affect variables associated with human health risk. In addition, PV are used for 10 years on 
average in Japan (AIRIA 2015), so there is about a 10-year delay in implementing decisions pertaining to vehicle exhaust emissions measures. For these reasons, we focused on the period of 1995-2005 and the choice of PV type.

\section{Materials and methods}

Figure 1 shows the procedure used for risk evaluation in our study.

\subsection{Case settings}

Table 1 presents the five cases defined in this study; it outlines the variables used and gives values for the two main drivers for risk. One driver is the choice of PV type, with changing holding PV composition ratio through time, and the other driver is vehicle emissions standards, with changing emission factors through time. The values of these two drivers differentiate these five cases, resulting in changes in other variables, as well as both DEP and $\mathrm{CO}_{2}$ emissions.

\subsubsection{Choice of passenger-vehicle type by consumers}

We set one of two possible choices of PV type in each case. In one set of cases, we let the choice of G-PV by consumers increase from 1995 to 2005, as occurred in Japan. In the other cases, we left the choice of PV type unchanged from 1995 to 2005.

Thus, in cases 1,4 , and 5 , the holding PV composition ratio between D-PV and G-PV was assumed to be 11:89\% (i.e., the same as in 1995 in Japan), while in cases 2 and 3, we assumed that G-PV were chosen more than in 1995, with a holding PV composition ratio between D-PV and G-PV of 4:96 \% (i.e., the same as in 2005 in Japan).
Fig. 1 Entire procedure of risk evaluation

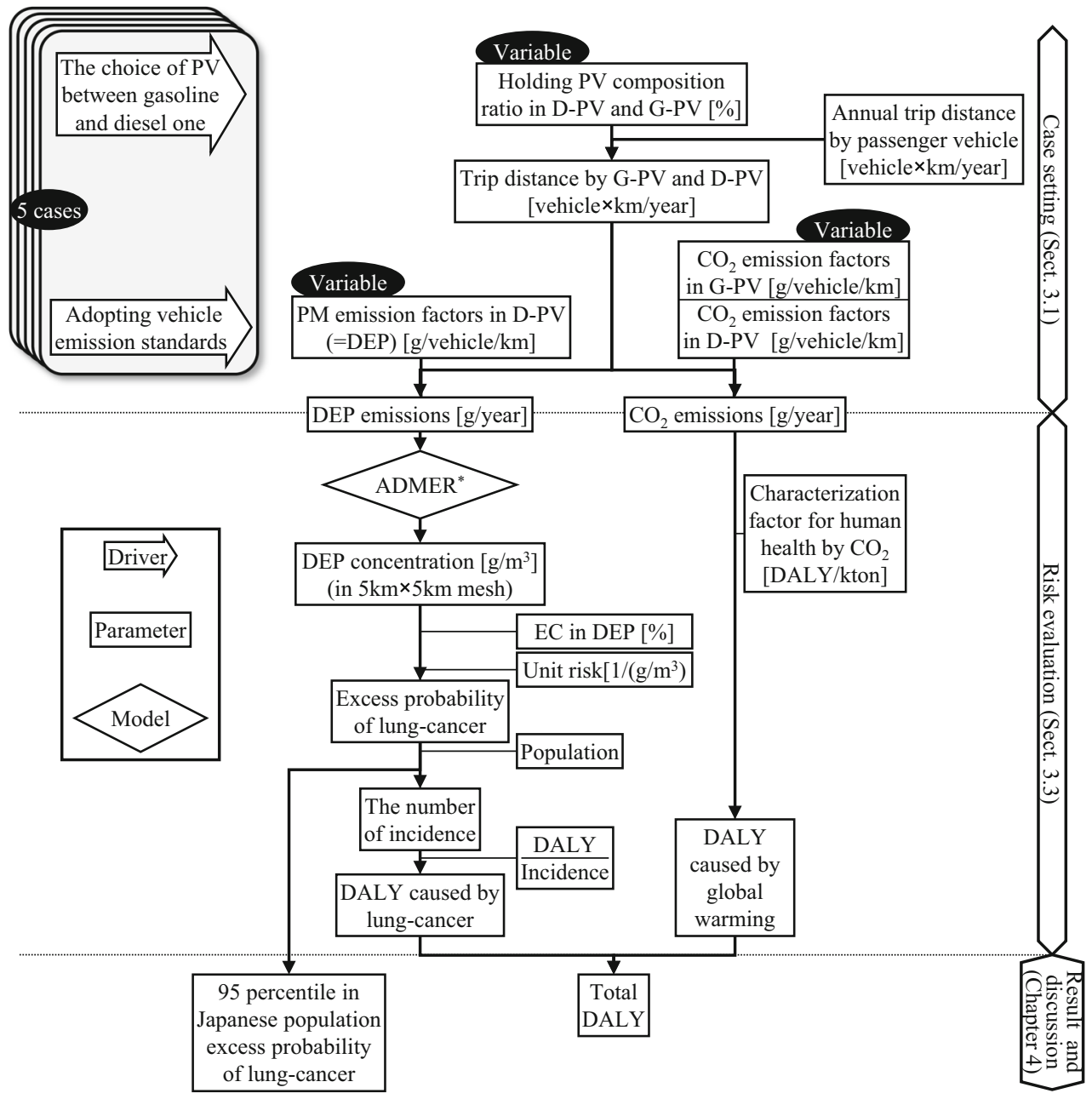

*ADMER: Atmospheric Dispersion Model for Exposure and Risk Assessment provided by AIST(National Institute of Advanced Industrial Science and Technology) 
Table 1 Case settings for PV choice and exhaust emissions standards employed in this study

\begin{tabular}{|c|c|c|c|}
\hline \multirow[t]{2}{*}{ Case } & \multirow[t]{2}{*}{ Outline } & \multicolumn{2}{|l|}{ Driver } \\
\hline & & PV preference & Emissions standards \\
\hline 1 & $\begin{array}{l}\text { PV choice between D-PV and G-PV was assumed to be unchanged } \\
\text { from 1995, with holding PV composition (D-PV:G-PV) of 11:89\% } \\
1994 \text { short-term standards were assumed, while emission factors were } \\
\text { assumed to remain at the actual ones for } 1995 \text { in Japan } \\
\text { We prepared this case as a baseline to compare effects of various } \\
\text { measures, so we set the holding PV composition and the emission } \\
\text { factors as in } 1995\end{array}$ & Unchanged from $1995^{\mathrm{d}}$ & 1994 short-term $^{a}$ \\
\hline 2 & $\begin{array}{l}\text { G-PV was assumed to be chosen more than 1995, with PV } \\
\text { composition (D-PV:G-PV) of 4:96 \% } \\
2005 \text { new long-term standards were assumed throughout, while } \\
\text { emission factors were those for } 2005 \text { in Japan } \\
\text { These measures reflect those for } 2005 \text { in Japan }\end{array}$ & $\begin{array}{l}\text { Greater choice of G-PV } \\
\text { compared with } 1995^{\mathrm{d}}\end{array}$ & 2005 new long-term ${ }^{b}$ \\
\hline 3 & $\begin{array}{l}\text { G-PV was assumed to be chosen more than 1995, with PV } \\
\text { composition (D-PV:G-PV) of 4:96 \% } \\
\text { The EURO } 4 \text { standard was adopted, and emission factors were } \\
\text { assumed to be the virtual ones calculated by PV for } 2005 \text { in Europe } \\
\text { (METI 2005). These measures are virtual ones for } 2005 \text { in Japan }\end{array}$ & $\begin{array}{l}\text { Greater choice of G-PV } \\
\text { compared with } 1995^{\mathrm{d}}\end{array}$ & EURO $4^{\mathrm{c}}$ \\
\hline 4 & $\begin{array}{l}\text { The choice of PV between D-PV and G-PV was assumed to be } \\
\text { unchanged from 1995, with PV composition (D-PV:G-PV) of } \\
\text { 11:89\% } \\
2005 \text { new long-term standards were assumed throughout, while } \\
\text { emission factors were those for } 2005 \text { in Japan }\end{array}$ & Unchanged from $1995^{\mathrm{d}}$ & 2005 new long-term ${ }^{\mathrm{b}}$ \\
\hline 5 & $\begin{array}{l}\text { The choice of PV between D-PV and G-PV was assumed to be } \\
\text { unchanged from 1995, with PV composition (D-PV:G-PV) of } \\
\text { 11:89\% } \\
\text { The EURO } 4 \text { standard was adopted, and emission factors were } \\
\text { assumed to be the virtual ones calculated by PV for } 2005 \text { in Europe } \\
\text { (METI 2005). These measures are virtual ones for } 2005 \text { in Japan }\end{array}$ & Unchanged from $1995^{\mathrm{d}}$ & EURO $4^{\mathrm{c}}$ \\
\hline
\end{tabular}

$G-P V$ gasoline passenger vehicle, $D-P V$ diesel passenger vehicle

${ }^{\mathrm{a}} \operatorname{MLIT}(2005 \mathrm{a}, \mathrm{b})$

b CEC (2002)

c EU (1998)

${ }^{\text {d }}$ METI (2005)

\subsubsection{Emission factors reflecting vehicle exhaust emissions standards}

The relationships between the employed drivers and the values used for emissions of the related variables are based on actual measures and observed values.

Here, we focus on the maximum value of PM emissions according to the vehicle emissions standards as well as on-road emission factors in the EU and Japan. The maximum value of PM emissions for D-PV in the EURO 4 standard is $0.025 \mathrm{~g} / \mathrm{km}$ (EU 1998), while the value in the Japanese new long-term standard since 2005 has been $0.013 \mathrm{~g} / \mathrm{km}$ (CEC 2002). Thus, the Japanese standard is more stringent. Based on a survey of actual emissions by vehicles in each market, the PM emission factor in England (in the EU) was $0.013 \mathrm{~g} / \mathrm{km}$ (METI 2005), while in Japan it was $0.008 \mathrm{~g} / \mathrm{km}$ at $30 \mathrm{~km} / \mathrm{h}$ (Dohi et al. 2012). We compare emission factors at $30 \mathrm{~km} / \mathrm{h}$ because the emission factor for G-PV in METI (2005), which was used as the reference for D-PV, was similar to the emission factors at $30 \mathrm{~km} / \mathrm{h}$ measured for $\mathrm{G}-\mathrm{PV}$ in Dohi et al. (2012). In contrast, the on-road $\mathrm{CO}_{2}$ emission factor in Japan was $166 \mathrm{~g} / \mathrm{km}$, while in England it was $133 \mathrm{~g} / \mathrm{km}$.

These relationships between emissions standards and actual emission factors show that adopting the lower maximum value for PM emissions is linked to a lower PM emission factor but higher emission factor for $\mathrm{CO}_{2}$. So, adopting these different vehicle emissions standards led to changes in emission factors, including for $\mathrm{CO}_{2}$, allowing us 
to explore their effects in the different cases, hence our selection of exhaust emissions as one of the main drivers.

Table 1 shows that we used either the 2005 new longterm standard (CEC 2002) or the EURO 4 standard (EU 1998) in our cases (except for case 1). In case 1, we assumed emissions standards based on the 1994 short-term standards, and emission factors were derived from actual ones in 1994 in Japan (Dohi et al. 2012; Namikawa et al. 2003). In cases 2 and 4, we set the 2005 new long-term standard for Japan, and the emission factors for D-PV and G-PV were assumed to be the same as the actual emission factors in 2005 in Japan (Dohi et al. 2012; Namikawa et al. 2003). In contrast, in cases 3 and 5, we used the EURO 4 standard, and the emission factors for D-PV were assumed to be the same as the virtual emission factors calculated from actual vehicle tests in England (METI 2005).

The emission factors for G-PV in the EURO 4 standard were assumed to be the same as the actual emission factors in 2005 in Japan, because the suspended particulate matter (SPM) limit was the same for the EURO 4 standard and the Japanese 2005 new long-term standard.

\subsection{Estimation of DEP and $\mathrm{CO}_{2}$ emissions}

DEP emissions are only included as PM emission from D-PV exhausts, and not for G-PV exhausts. Both PV types emit $\mathrm{CO}_{2}$. We assumed that the annual trip distance in a D-PV and G-PV were the same. Thus, the ratio between the annual trip distance in D-PV and G-PV was assumed to be the same as the holding PV composition ratio in each case. To estimate real exhaust outputs, we used emission factors and trip distances based on velocity for each Japanese prefecture.

The emission amount $E_{m, n, o}$ (g/year) for case $m$, substance $n$, and prefecture $o$ was calculated using Eq. (1):

$E_{m, n, o}=\sum_{p} \sum_{q}\left(\mathrm{HPVC}_{m, p} \times \mathrm{TD}_{o, q} \times \mathrm{EF}_{m, n, p, q}\right)$,

where $m$ indicates the case $(1,2,3,4,5), n$ the substance (DEP, $\mathrm{CO}_{2}$ ), $o$ the prefecture in Japan (Japan has 47 prefectures), $p$ the vehicle type (D-PV, G-PV), $q$ the velocity class defined in $5 \mathrm{~km} / \mathrm{h}$ intervals, $E_{m, n, o}$ the annual emission amount (g/year) for case $m$, substance $n$, and prefecture $o, \mathrm{HPVC}_{m, p}$ the holding passenger vehicle composition ratio (\%) for case $m$ and vehicle type $p, \mathrm{TD}_{o, q}$ the annual trip distance (vehicle $\times \mathrm{km} / \mathrm{year}$ ) for prefecture $o$ and velocity class $q$, and $\mathrm{EF}_{m, n, p, q}$ the emission factor $(\mathrm{g} / \mathrm{km})$ for case $m$, substance $n$, vehicle type $p$, and velocity class $q$.

The derivation of $\mathrm{TD}_{o, q}$ (vehicle $\times \mathrm{km} /$ year) is presented in Appendix 1 of the Electronic Supplementary Material (ESM) (MLIT 2005a, b), while $\mathrm{EF}_{m, n, p, q}(\mathrm{~g} / \mathrm{km})$ is shown in Appendix 2 of the ESM (Dohi et al. 2012; Namikawa et al. 2003; METI 2005).

\subsection{Human health risks caused by lung cancer and global warming}

\subsubsection{Lung cancer caused by inhalation exposure to EC in $D E P$}

To estimate DEP spatial concentrations $\left(\mathrm{g} / \mathrm{m}^{3}\right)$, we employed the software Atmospheric Dispersion Model for Exposure and Risk Assessment (ADMER version 2.6, Higashino et al. 2003). ADMER is based on a plume-puff model using general air pollutant dispersion theory. An outline of ADMER is given in Appendix 3 of the ESM. The parameters required in ADMER are described in Appendix 4 of the ESM.

To evaluate the risk caused by exposure to DEP, we followed the method used by the California EPA (1998). We focused on lung cancer caused by inhalation exposure to EC in DEP. The concentration of EC, given by $D_{m, \mathrm{EC}}$, for various cases and mesh sizes $(r)$, was calculated using Eq. (2):

$D_{m, \mathrm{EC}, r}=0.697 \times D_{m, \mathrm{DEP}, r}$,

where $r$ is the mesh size (for a mesh defined as a $5 \times 5 \mathrm{~km}^{2}$ grid for Japan in this study), with values obtained from ADMER, $D_{m, \mathrm{EC}, r}$ is the EC concentration $\left(\mathrm{g} / \mathrm{m}^{3}\right)$ for case $m$ and the $r$-th mesh, and $D_{m, \mathrm{DEP}, r}$ is the DEP concentration $\left(\mathrm{g} / \mathrm{m}^{3}\right)$ for case $m$ and the $r$-th mesh estimated by ADMER. Note that the factor 0.697 is the ratio of EC in DEP for small cars (PV in this study) (Yamamoto et al. 2008).

The excess lifetime lung cancer risk, $\mathrm{ER}_{m, r, s}$ for case $m$, the $r$-th mesh, and cancer type $s$ (lung cancer), was calculated using Eq. 3. The DALY impact caused by inhalation of EC, DALY $_{m, \mathrm{EC}}$ for case $m$ was calculated using Eq. 4 . In this study, we employed the geometric mean of the unit risk: $\mathrm{UR}_{\mathrm{EC}, s}=6 \times 10^{-4}\left[1 /\left(\right.\right.$ lifetime$\left.\left.-\mu \mathrm{g} / \mathrm{m}^{3}\right)\right]$ for lung cancer caused by EC, derived from the California EPA (1998). The (DALY/incidence) $)_{t}$ value for lung cancer was 12.587 DALY/incidence, as shown in Itsubo and Inaba (2010).

$\mathrm{ER}_{m, r, s}=D_{m, \mathrm{EC}, r} \times \mathrm{UR}_{\mathrm{EC}, s}$

where $s$ is the cancer type (lung cancer), $E R_{m, r, s}$ is the excess lifetime cancer risk for case $m$, mesh $r$, and cancer type $s$, and $\mathrm{UR}_{\mathrm{EC}, s}$ is the unit risk $\left[1 /\left(\right.\right.$ lifetime$\left.\left.-\mu \mathrm{g} / \mathrm{m}^{3}\right)\right]$ for EC causing cancer type $s$.

$\mathrm{DALY}_{m, \mathrm{EC}}=\sum_{r}\left\{\mathrm{ER}_{m, r, s} \times\right.$ Population $\left._{r} \times\left(\frac{\mathrm{DALY}}{\text { incidence }_{t}}\right)_{t}\right\}$,

where $t$ is the incidence of lung cancer, Population is $_{r}$ the population within the mesh (MIAC 2005), DALY $m$,EC is the DALY impact of EC for case $m$, and DALY/incidence is the DALY impact per incidence. 
Note that the excess lifetime lung cancer risk at the 95th percentile in the Japanese population means that $95 \%$ of Japanese people were under the excess risk threshold.

The reason for adopting the geometric mean of unit risk according to the California EPA was that the geometric mean provides information on the central tendency of the range; it should not be confused with the best estimate as identified from the available calculations. Furthermore, the DALY impact per incidence in Itsubo and Inaba (2010) was adopted because this value was modified using the available medical statistics in Japan from the original value of DALY per incidence in Murray and Lopez (1996).

\subsubsection{Human health risk caused by global warming linked to $\mathrm{CO}_{2}$ emissions}

We estimated the DALY impact as the human health risk caused by global warming linked to $\mathrm{CO}_{2}$ emissions, after Schryver et al. (2009). Schryver et al. estimated a characterization factor (CF) (DALY/kton) at the endpoint for malaria, diarrhea, malnutrition, drowning, and cardiovascular diseases. We used a CF of $1.76 \times 10^{-2}$ (DALY/ t- $\mathrm{CO}_{2 \text {-eq }}$ ), which was calculated with no age weighting and a $0 \%$ discount ratio (egalitarian). In Sect. 3.3.1, the DALY impact for EC exposure was evaluated using the (DALY/ incidence) $)_{t}$ value for lung cancer (Itsubo and Inaba 2010) with no age weighting and a $0 \%$ discount ratio as well. We could therefore compare the two DALY values. The DALY impact for $\mathrm{CO}_{2}$-related health risks, $\mathrm{DALY}_{m, \mathrm{CO}_{2}}$, for each case was calculated using Eq. (5):

$\mathrm{DALY}_{m, \mathrm{CO}_{2}}=\mathrm{CF}_{\mathrm{CO}_{2}} \times \sum_{o} E_{m, \mathrm{CO}_{2}, o}$,

where DALY $\mathrm{C}_{m, \mathrm{CO}_{2}}$ is the DALY impact for $\mathrm{CO}_{2}$-related health risks for case $m$ and $\mathrm{CF}_{\mathrm{CO}_{2}}$ is the characterization factor (DALY/kton) for $\mathrm{CO}_{2}$ emissions on DALY.

This DALY ${ }_{m, \mathrm{CO}_{2}}$ reflects $\mathrm{CO}_{2}$ emissions in Japan.

\section{Results and discussion}

\subsection{Estimation of vehicle exhaust emissions for five cases}

Table 2 presents the results for each case, giving both parameters and estimated emission amounts. The PM and $\mathrm{CO}_{2}$ emission factors in Table 2 are for $30 \mathrm{~km} / \mathrm{h}$ in each case (Dohi et al. 2012; METI 2005; Namikawa et al. 2003). The method used to calculate these emission factors and our calculation results are presented in Appendix 1 of the ESM.

Because case 1 was defined as a reference case for comparing the effects of control measures, we set the holding PV composition ratio and the emission factors as in 1995, before any measures were implemented. These settings led to higher DEP and $\mathrm{CO}_{2}$ emission estimates than for the other four cases. DEP emissions were around 44 times higher than for case 2, which had the lowest DEP emissions. $\mathrm{CO}_{2}$ emissions were around 1.3 times higher than for case 5, which had the lowest $\mathrm{CO}_{2}$ emissions among our cases. In fact, this case does not represent the risk situation in 1995 in Japan, because factors other than emission factors and holding PV composition ratio were the same as those in 2005 in Japan. However, our research objective was not to reevaluate human health risks in 1995; rather, these settings provide a reference to evaluate the effects of different holding PV composition ratios and emission factors on DEP and $\mathrm{CO}_{2}$ emissions.

In case 2, we assumed that consumers chose G-PV more than in 1995 and Japan adopted the 2005 new long-term standards. As a result of introducing these measures, the holding PV composition ratio and emission factors were assumed to have the same values as in 2005 in Japan. We therefore regard this case as a reevaluation of the combined measures taken in 2005 in Japan. This combination of holding PV composition ratio and emission factors led to the lowest estimated DEP emissions of 226.6 t/year. $\mathrm{CO}_{2}$ emissions were estimated as $107.6 \times 10^{6} \mathrm{t} / \mathrm{year}$.

In case 3, we assumed G-PV were chosen more ofter, as in case 2, but adopted the EURO 4 standard. DEP emissions were estimated as $363.9 \mathrm{t} / \mathrm{year}$, and $\mathrm{CO}_{2}$ emissions were estimated as $105.8 \times 10^{6} \mathrm{t} /$ year. DEP emissions in case 3 were higher than in case 2 , while $\mathrm{CO}_{2}$ emissions were lower. We aimed to evaluate the difference in these vehicle emissions standards in terms of emission amount and human health risk.

In case 4, we assumed that the choice of PV type remained unchanged from 1995 and adopted the 2005 new long-term standards. DEP emissions were estimated as $614.1 \mathrm{t} /$ year, and $\mathrm{CO}_{2}$ emissions were estimated at $109.9 \times 10^{6} \mathrm{t} /$ year. This case had the same holding PV composition ratio as case 1 , but a different emission factor, so the difference in emissions indicates the reductions achieved by only improving emission factors from 1995 to 2005.

In case 5, we assumed that the choice of PV type remained unchanged from 1995 but adopted the EURO 4 standard. There were differences from case 2 for both drivers. With this unchanged choice of PV type from 1995 and adopting the EURO 4 standard, the emission factors and holding PV composition ratio led to the lowest estimated $\mathrm{CO}_{2}$ emissions of $105.0 \times 10^{6} \mathrm{t} /$ year. However, the estimated DEP emissions of $986.1 \mathrm{t} /$ year were the highest.

Here, we focus on the emission factors in case 2 (and case 4). Generally, D-PV are more fuel efficient, resulting in lower $\mathrm{CO}_{2}$ emissions for D-PV than for G-PV (EERE 
Table 2 Variables and exhaust emissions used for each case

\begin{tabular}{|c|c|c|c|c|c|c|c|c|}
\hline \multirow[t]{4}{*}{ Case } & \multicolumn{6}{|c|}{ Variables } & \multirow{2}{*}{\multicolumn{2}{|c|}{ Estimated annual exhaust emissions amount }} \\
\hline & \multicolumn{4}{|c|}{ Emission factors } & \multicolumn{2}{|c|}{ Holding PV composition ratio (\%) } & & \\
\hline & \multicolumn{2}{|c|}{$\mathrm{PM}(\mathrm{mg} / \mathrm{km})^{\mathrm{a}}$} & \multicolumn{2}{|c|}{$\mathrm{CO}_{2}(\mathrm{~g} / \mathrm{km})^{\mathrm{a}}$} & \multirow[t]{2}{*}{ D-PV } & \multirow[t]{2}{*}{ G-PV } & \multirow[t]{2}{*}{ DEP (t/year) } & \multirow[t]{2}{*}{$\mathrm{CO}_{2}\left(10^{6} \times \mathrm{t} /\right.$ year $)$} \\
\hline & D-PV & G-PV & D-PV & G-PV & & & & \\
\hline 1 & 126 & 1.158 & 250 & 178 & 11 & 89 & 9947.4 & 135.3 \\
\hline 2 & 8 & 0.417 & 196 & 145 & 4 & 96 & 226.6 & 107.6 \\
\hline 3 & 13 & 0.417 & 133 & 145 & 4 & 96 & 363.9 & 105.8 \\
\hline 4 & 8 & 0.417 & 196 & 145 & 11 & 89 & 614.1 & 109.9 \\
\hline 5 & 13 & 0.417 & 133 & 145 & 11 & 89 & 986.1 & 105.0 \\
\hline
\end{tabular}

$D-P V$ diesel passenger vehicle; $G-P V$ gasoline passenger vehicle; $D E P$ diesel exhaust particle

${ }^{a} \mathrm{PM}$ and $\mathrm{CO}_{2}$ emission factors are at $30 \mathrm{~km} / \mathrm{h}$, in this instance

2015). However, the emission factors calculated in case 2 show the reverse relationship. The values used in case 2 came from an actual PV survey by Dohi et al. (2012), who reported values where both $\mathrm{PM}$ and $\mathrm{CO}_{2}$ emission factors for D-PV were worse than for G-PV. The lesser improvement in $\mathrm{CO}_{2}$ emission factors for D-PV is thought to reflect the decrease in D-PV numbers. A decrease in D-PV sales in Japan discouraged installation of updated technologies in D-PV in the market (METI 2005). It is also important to note that we employed emission factors without any modifications.

\subsection{Risk evaluation results for five cases}

Table 3 presents the results of our risk evaluation: the excess lifetime lung cancer risk at the 95th percentile in the Japanese population, DALY impact from lung cancer linked to EC inhalation exposure, DALY impact from global warming linked to $\mathrm{CO}_{2}$ emission, and total DALY impact reflecting both EC- and $\mathrm{CO}_{2}$-related health risks.

Our results show that the DALY impact of EC emissions was lower by two orders of magnitude than the DALY impact of $\mathrm{CO}_{2}$ emissions. These results largely depend on the case setting on the choice of PV types and emission factors, endpoints and other inherent factors like the characterization factors (Schryver et al. 2009) in our study. As such, understanding the uncertainty in our results is a very important issue. However, given that the purpose of this study is to compare cases using the same method, we decided that establishing the variance in the risk stemming from $\mathrm{CO}_{2}$ emissions lay outside the scope of this study.

In case 1 , defined as a reference case, the DALY impact of lung cancer, DALY impact of global warming, and total DALY impact values were much larger than for the other

Table 3 Evaluation results of two indices of human health risk

\begin{tabular}{|c|c|c|c|c|}
\hline \multirow[t]{2}{*}{ Case } & \multicolumn{2}{|l|}{$\mathrm{EC}^{\mathrm{a}}$} & \multirow{2}{*}{$\begin{array}{l}\mathrm{CO}_{2} \\
\text { DALY impact of global } \\
\text { warming }\left(10^{3} \times \text { DALY }\right)^{\mathrm{c}}\end{array}$} & \multirow{2}{*}{$\begin{array}{l}\text { Total DALY } \\
\left(10^{3} \times \text { DALY }\right)\end{array}$} \\
\hline & $\begin{array}{l}\text { Excess lifetime lung cancer risk } \\
\text { at } 95 \text { percentile in Japanese population }{ }^{\mathrm{a}}\end{array}$ & $\begin{array}{l}\text { DALY impact of lung } \\
\text { cancer }\left(10^{3} \times \text { DALY }\right)^{b}\end{array}$ & & \\
\hline 1 & $5.83 \times 10^{-4}$ & 75 & 2382 & 2457 \\
\hline 2 & $9.96 \times 10^{-5}$ & 12 & 1894 & 1905 \\
\hline 3 & $1.03 \times 10^{-4}$ & 13 & 1862 & 1874 \\
\hline 4 & $1.04 \times 10^{-4}$ & 13 & 1934 & 1947 \\
\hline 5 & $1.23 \times 10^{-4}$ & 15 & 1848 & 1863 \\
\hline
\end{tabular}

$E C$ elemental carbon (from diesel exhaust particle exposure), DALY disability-adjusted life years

${ }^{\text {a }}$ Unit risk from California EPA (1998)

b DALY per incidence (of lung cancer) from Itsubo and Inaba (2010)

${ }^{c}$ DALY per $\mathrm{CO}_{2}$ emission from Schryver et al. (2009) 
four cases, because we used emission factors from 1995. In comparison with the other cases, the DALY impact related to EC emissions was 5-6 times larger, while the DALY impact related to $\mathrm{CO}_{2}$ emissions was approximately 1.2-1.3 times larger. Clearly, vehicle exhaust control measures have reduced the burden on human health.

\subsubsection{Risk evaluation results arranged by excess lifetime cancer risk and total DALY impact}

Based on the risk evaluation results in Table 3, we plot all the cases in Fig. 2, where the horizontal axis indicates the excess lifetime cancer risk and the vertical axis indicates the total DALY impact. The gray region in Fig. 2 represents values under $10^{-5}$ or the virtually safe dose (Gaylor 1989) for excess lifetime lung cancer risk.

In Fig. 2, we see that case 2 was evaluated at $9.96 \times 10^{-5}$, the lowest value for excess lifetime lung cancer risk at the 95 th percentile in the Japanese population. Because case 2 reflects the 2005 new long-term standards, which are relatively stringent in terms of PM, as well as the lower holding D-PV composition ratio (D-PV having higher PM emissions than G-PV) in 2005 in Japan, we can surmise that past Japanese exhaust control measures were designed to reduce air pollution. However, the excess lifetime lung cancer risk at the 95th percentile in the Japanese population in case 2 exceeded $10^{-5}$, indicating that we need to reduce PM further to reduce human health risk.

We also focus on the plot for the total DALY impact, for which case 5 was evaluated as having the lowest total DALY impact of $1863 \times 10^{3}$. Case 5 also had the lowest $\mathrm{CO}_{2}$ emissions. The reduction in total DALY between

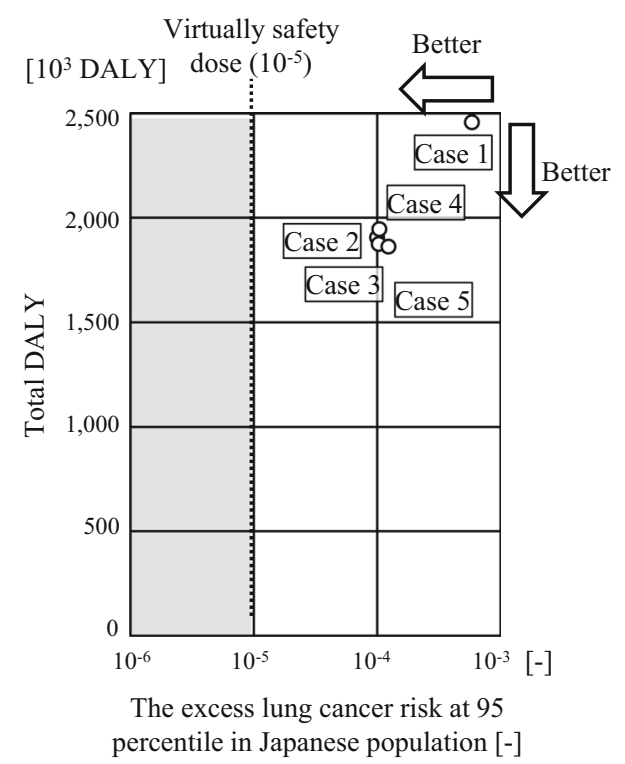

Fig. 2 Result of risk evaluation focusing on the total DALY and the excess lung cancer risk case 1 and 5 was $594 \times 10^{3}$, representing a decrease of $76 \%$. For cases 1 and 2 , in which the total DALY impact was related to EC emissions, this reduction was $552 \times 10^{3}$, representing a decrease of up to $78 \%$ compared with case 1. Our risk evaluation results suggest that $\mathrm{CO}_{2}$ reduction was more effective for decreasing the total DALY impact than EC reduction. Similar results were found for excess lung cancer risk: It was reduced by up to $76 \%$ compared with case 1 . However, the DALY values related to both $\mathrm{EC}$ and $\mathrm{CO}_{2}$ emissions were $1863 \times 10^{3}$ DALY. Clearly, to reduce the total DALY impact, we need to consider a combination of air pollution management and global warming management in the future.

Lastly, the difference in total DALY between cases 2 and 5 was evaluated as $42 \times 10^{3}$. Thus, the difference between cases 1 and 5 was 14.1 times higher than that between cases 2 and 5, suggesting lesser effects between cases 2 and 5 .

These results show that the difference in emission factors between 1995 and 2005 reduced the DALY impact to a larger extent than the differences between vehicle emissions standards or the choice of PV type. To further evaluate technological improvements that reduce emission factors, we need additional information with improved time resolution.

\subsubsection{Comparison between DALY impact of lung cancer versus global warming}

Based on the risk evaluation results in Table 3, we plot four cases in Fig. 3, excluding case 1, to look at the cases adopting the 2005 emissions standards. In Fig. 3, case 2 appears at the origin, while the horizontal axis indicates the DALY difference from case 2 related to global warming and the vertical axis indicates the DALY difference from case 1 related to air pollution impacts on health. Thus, Fig. 3 clearly shows the risk trade-off for each case against

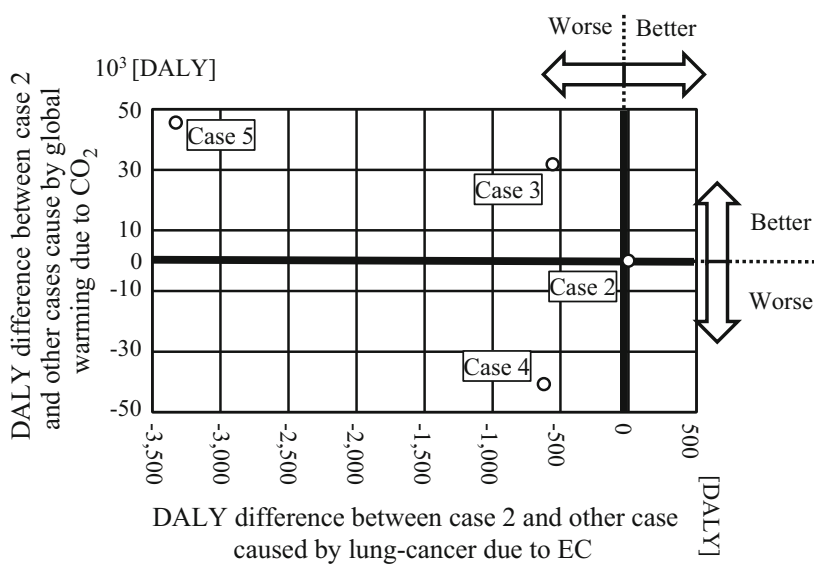

Fig. 3 Case comparison based on DALY by $\mathrm{CO}_{2}$ and EC 
the origin. In addition, Fig. 3 can be used to identify the effects of past measures. Case 3 moves in a direction with worse air pollution but better global warming risk management. Given that the difference between cases 2 and 3 is the adoption of the 2005 new long-term standard versus the EURO 4 standard, emission factors under these different exhaust emissions standards are the driving factor here. Quantitatively, adopting the EURO 4 standard instead of the 2005 new long-term standard led to a reduction of $31.9 \times 10^{3}$ DALY linked to global warming, but an increase of $0.6 \times 10^{3}$ DALY linked to lung cancer.

Likewise, changing the holding PV composition ratio is the difference between cases 3 and 5. Comparing the 1995 holding PV composition ratio of 11:89 \% (D-PV:G-PV) with a shift to $4: 96 \%$ in 2005 resulted in a $13.8 \times 10^{3}$ DALY reduction in health risk related to global warming, but a $2.8 \times 10^{3}$ DALY increase in lung cancer risk. From another perspective, the differences among the cases indicate how to decrease the targeted risks using a certain driver or variable change. The difference between cases 2 and 4 reflects the choice of PV type, with DALY estimates in case 4 being lower than in case 2, suggesting that decreasing D-PV numbers is one way to decrease the DALY values.

\section{Conclusions}

We characterized past exhaust control measures based on a human health risk evaluation. We constructed a human health risk evaluation model for lung cancer caused by EC and health damage caused by global warming linked to $\mathrm{CO}_{2}$. We built both actual and hypothetical cases based on the choice of PV type and vehicle emissions standards determining the holding PV composition ratio and emission factors. From our risk evaluation, we could evaluate exhaust emission policy and evaluate past measures in a quantitative way. We summarize our results in two main conclusions:

1. Introducing exhaust policies from 1995 onwards resulted in reduced human health risks stemming from $\mathrm{CO}_{2}$ and EC (included in PM) emissions. Case 3, with the same PV composition as in case 2 but using the EURO 4 instead of 2005 new long-term standard, exhibited a reduced DALY impact of global warming by $31.9 \times 10^{3}$ but an increase of $0.6 \times 10^{3}$ DALY for lung cancer. These results show that vehicle emissions standards lead to a risk trade-off. This was also the case for the PV composition. To evaluate risk tradeoffs, we illustrate our results on horizontal and vertical axes to compare the relative DALY values based on the two different risks.
2. Settings based on actual measures and the quantitative results showed that past Japanese decisions with regards to exhaust emission control had the intention of preferentially reducing air pollution. Because case 2 exhibited the lowest risk related to air pollution, its excess lifetime lung cancer risk at the 95th percentile in the Japanese population was $9.96 \times 10^{-5}$, while the DALY impact for lung cancer was evaluated as $12 \times 10^{3}$. We set case 2 to have the 2005 long-term standard, which is relatively stringent in terms of PM, as well as a lower D-PV composition, as for 2005 in Japan. Based on case 2, cases 3 and 5 would slightly decrease the human health risk related to global warming, but would increase the human health risk related to air pollution. Case 4 would slightly increase both risks. Thus, we examined and characterized exhaust policies based on case 1 .

Acknowledgments This research was supported by the Environment Research and Technology Development Fund (C-1004) of the Ministry of the Environment, Japan (2010-2012).

Open Access This article is distributed under the terms of the Creative Commons Attribution 4.0 International License (http://creativecommons. org/licenses/by/4.0/), which permits unrestricted use, distribution, and reproduction in any medium, provided you give appropriate credit to the original author(s) and the source, provide a link to the Creative Commons license, and indicate if changes were made.

\section{References}

AIRIA (Automobile Inspection and Registration Information Association) (2015) Historical data of average use year by vehicle type. https://www.airia.or.jp/publish/statistics/ao1lkc00000000z 4-att/03_32.pdf. Accessed 18 Oct 2015

California EPA (Environmental Protection Agency) (1998) For the "proposed identification of diesel exhaust as a toxic air contaminant" part B: health risk assessment for diesel exhaust. http://www.arb.ca.gov/regact/diesltac/partb.pdf. Accessed 16 Oct 2015

Cames M, Helmers E (2013) Critical evaluation of the European diesel car boom - global comparison, environmental effects and various national strategies. Env Sci Eur 25:15

CEC (Central Environment Council, Japan) (1997) Future policy for motor vehicle exhaust emission reduction (second report). https:// www.env.go.jp/council/former/tousin/t07-h0901.pdf. Accessed 4 Dec 2015

CEC (Central Environment Council, Japan) (2002) Future policy for motor vehicle exhaust emission reduction (fifth report). https://www. env.go.jp/en/air/aq/mv/vehicle-fifth.pdf. Accessed 28 Oct 2015

Dohi M, Sone S, Takimoto M, Ogawa T, Namikawa Y (2012) Grounds for the calculation of motor vehicle emission factors using environment impact assessment of road project etc. (revision of 2010). In: Technical note of National Institute for Land and Infrastructure Management, Japan, No. 671

EERE (Office of Energy Efficiency and Renewable Energy, U.S.) About diesels. https://www.fueleconomy.gov/feg/di_diesels. shtml. Accessed 18 Oct 2015 
EU (1998) directive 98/69/EC of the European parliament and of the council of 13 October 1998 relating to measures to be taken against air pollution by emissions from motor vehicles and amending Council Directive 70/220/EEC. http://eur-lex.europa. eu/resource.html?uri=cellar:9ee5d16b-1a4a-4a72-ac90-5e3a0bb1d 745.0008.02/DOC_1andformat=PDF. Accessed 16 Oct 2015

Gaylor DW (1989) Preliminary estimates of the virtually safe dose for tumors obtained from the maximum tolerated dose. Regul Toxicol Pharmacol 9:101-108

Higashino H, Kitabayashi K, Inoue K, Mita K, Yonezawa K (2003) Development of an atmospheric dispersion model for exposure and risk assessment (ADMER). J Jpn Soc Atmos Environ 38:100-115

Itsubo N, Inaba A (2010) LIME2-life-cycle impact assessment method based on endpoint modeling. Maruzen, Japan

Linkov I, Anklam E, Collier ZA, DiMase D, Renn O (2014) Risk-based standards: integrating top-down and bottom-up approaches. Environ Syst Decis 34:134-137

METI (Ministry of Economy, Trade and Industry, Japan) (2005) Report on the investigative commission for clean-diesel-vehicle prevalence and future vision (in Japanese). http://www.meti.go. jp/report/downloadfiles/g50418b01j.pdf. Accessed 16 Oct 2015

MIAC (Ministry of Internal Affairs and Communications, Japan) (2005) National population census. http://e-stat.go.jp/SG2/eStat GIS/page/download.html. Accessed 16 Oct 2015
MLIT (Ministry of Land, Infrastructure, Transport and Tourism, Japan) (2005a) Annual report of road transport statistics. http:// www.mlit.go.jp/k-toukei/syousaikensaku.html. Accessed 16 Oct 2015

MLIT (Ministry of Land, Infrastructure, Transport and Tourism, Japan) (2005b) Road transportation census 2005. Maruzen, Japan

Murray C, Lopez AD (1996) The global burden of disease. Harvard University Press, Cambridge

Namikawa Y, Takai Y, Ohsihiro N (2003) Calculation base of motor vehicle emission factors, Technical note of National Institute for Land and Infrastructure Management, Japan, No. 141

Schryver A, Brakkee KW, Goedkoop MJ, Huijbregts M (2009) Characterization factors for global warming in life cycle assessment based on damages to humans and ecosystems. Environ Sci Technol 43:1689-1696

Tengs TO, Adams ME, Pliskin JS, Safran DG, Siegel JE, Weinstein MC, Graham JD (1995) Five-hundred life-saving interventions and their cost-effectiveness. Risk Anal 15:369-390

Yamamoto K, Kuwana J, Mizusawa Y, Tohno S (2008) Estimation of elemental carbon emission and spatial distribution of atmospheric concentration in Kansai area. J Jpn Soc Atmos Environ $43: 245-256$ 